\title{
“Eu não deveria ter saído de lá! Gosto de estudar!”: Os desafios de pessoas com Transtorno do Espectro Autista para escolarização
}

\author{
"I shouldn't have gotten out of there! I like to study!": The challenges of people with Autism \\ Spectrum Disorder for schooling \\ "Yo no debería haber salido de allí! Me gusta estudiar!": Los desafios de las personas com \\ trastorno del espectro autista para la escolarización
}

Recebido: 05/04/2021 | Revisado: 12/04/2021 | Aceito: 16/04/2021 | Publicado: 01/05/2021

Ivanise Gomes de Souza Bittencourt
ORCID: https://orcid.org/0000-0002-9416-3964
Universidade Federal de Alagoas, Brasil
E-mail: ivanise.gomes@eenf.ufal.br
Neiza de Lourdes Frederico Fumes
ORCID: https://orcid.org/0000-0002-1913-4784
Universidade Federal de Alagoas, Brasil
E-mail: neizaf@yahoo.com

\begin{abstract}
Resumo
Este estudo analisou as vivências escolares de pessoas adultas com Transtorno do Espectro Autista (TEA) para evidenciar aspectos que as potencializaram e/ou as fragilizaram no prosseguimento ou interrupção da escolaridade. A abordagem histórico-cultural de Vygotski constituiu o aporte teórico desta pesquisa, que utilizou a narrativa de vida e teve como unidade de análise a categoria vivência. $\mathrm{O}$ estudo envolveu quatro indivíduos oralizados, com idades entre 30 e 36 anos, sendo três do sexo masculino e um do sexo feminino, no município de Maceió-Alagoas-Brasil. Os dados foram produzidos a partir de entrevistas narrativas, e, dada a diversidade das habilidades comunicativas de pessoas com TEA, utilizou-se o Sistema de Comunicação Alternativa para Letramento de Pessoas com Autismo (SCALA), uma tecnologia assistiva, de forma suplementar, a partir do seu módulo de Narrativas Visuais para a construção das histórias dos seus espaços escolares. Constatou-se que os participantes vivenciaram as fragilidades do sistema escolar para lidar com suas especificidades e que as vivências nos espaços escolares refletiram nas suas escolaridades, com impactos no desenvolvimento, constituição, posição social e nas apropriações e atividades no mundo. Entretanto, as potencialidades da mobilização das mães para a inclusão escolar e social constituíram seus alicerces de vida. Sendo os participantes com TEA parte da Situação Social de Desenvolvimento (SSD) e das suas relações com meio, as situações e os acontecimentos vivenciados influenciaram no desenvolvimento psicológico e lhes foram orientadores em seus posicionamentos e nas suas características pessoais.
\end{abstract}

Palavras-chave: Transtorno do espectro autista; Narrativas de vida; Escola.

\begin{abstract}
This study analyzed the school experiences of adult people with Autism Spectrum Disorder (ASD) to evidence aspects that enhanced them and/or weakened them in the continuation or interruption of schooling. Vygotski's historical-cultural approach constituted the theoretical contribution of this research, which used the narrative of life and had as unit of analysis the category of experience. The study involved four individuals oralized, aged between 30 and 36 years, three male and one female, in the municipality of Maceió-Alagoas-Brazil. The data were produced from narrative interviews, and, given the diversity of the communicative skills of people with ASD, the Alternative Communication System for Literacy of People with Autism (SCALA) was used, a technology assisted, in a supplementary way, from its Visual Narratives module to construct the stories of their school spaces. It was found that the participants experienced the weaknesses of the school system to deal their specificities and that the experiences in school spaces reflected in their schooling, with impacts on development, constitution, social position and appropriations and activities in the world. However, the potentialities of the mobilization of mothers for school and social inclusion constituted their foundations of life. Since the participants with ASD were part of the Social Situation of Development (SSD) and their relations with the environment, the situations and events experienced influenced the psychological development and were guiding them in their positions and personal characteristics.
\end{abstract}

Keywords: Autism spectrum disorder; Life Narratives; School. 


\begin{abstract}
Resumen
Este estudio analizó las experiencias escolares de las personas adultas con Trastorno del Espectro Autista (TEA) para evidenciar aspectos que las mejoraron y/o debilitaron en la continuación o interrupción de la escolarización. El enfoque histórico-cultural de Vygotski constituyó la contribución teórica de esta investigación, que utilizó la narrativa de la vida y tenían como unidad de análisis la categoría de experiencia. La insvestigacion abarcó cuatro individuos oralizados, de entre 30 y 36 años, tres hombres y una mujer, en el municipio de Maceió-Alagoas-Brasil. Los datos fueron producidos a partir de entrevistas narrativas, y, dada la diversidad de las habilidades comunicativas de las personas con TEA, se utilizó el Sistema de Comunicación Alternativa para la Alfabetización de Personas con Autismo (SCALA), una tecnología asistida, de manera complementaria, desde su módulo de Narrativa Visual para construir las historias de sus espacios escolares. Se encontró que los participantes experimentaron las debilidades del sistema escolar para tratar de sus especificidades y que las experiencias en los espacios escolares reflejadas en su escolarización, con impactos en el desarrollo, constitución, posición social y apropiaciones y actividades en el mundo. Sin embargo, las potencialidades de la movilización de las madres para la inclusión escolar y social constituían sus fundamentos de vida. Dado que los participantes con TEA formaban parte de la Situación Social del Desarrollo (SSD) y sus relaciones con el medio ambiente, las situaciones y eventos experimentados influyeron en el desarrollo psicológico y los guiaron en sus posiciones y características personales.
\end{abstract}

Palabras clave: Trastorno del espectro autista; Narrativas de vida; Escuela.

\title{
1. Introdução
}

Devido as especificidades de Pessoas com Transtorno do Espectro Autista (TEA), como déficit na socialização, comunicação e comportamento, elas comumente encontram dificuldades que refletem na participação social (Chen et al., 2015). Para Vygotski (1934/1997c) o desenvolvimento e a aprendizagem do indivíduo, são processos com raízes sociais, portanto, sócio históricos e que se constituem nas interações no espaço social.

Deste modo, para a compreensão das vivências escolares de pessoas com TEA, é necessário analisar os seus fundamentos históricos e a narração possibilita conhecer os acontecimentos e sentidos para os indivíduos (Vygotski, 1916/1999). Através das narrativas os indivíduos expressam seus modos de ser/estar/relacionar com o mundo, constituindo sua subjetividade.

A abordagem Histórico-Cultural aponta a atividade e as condições concretas de vida e educação, como elementos necessários para a compreensão do desenvolvimento psíquico, que é repleto de movimentos ascendentes e descendentes nas contradições vividas pelo indivíduo em seu universo cultural. Assim, Vygotski (1933/2012b) explica que o estudo das vivências, entendido como uma averiguação da relação interna de uma pessoa com a realidade. É a unidade entre ambos e a tradução do que o indivíduo pensa, sente e mantêm com o seu meio, pois sendo parte da Situação Social de Desenvolvimento (SSD), as situações e os acontecimentos vivenciados influenciam no desenvolvimento psicológico e lhes são orientadores em seus posicionamentos e nas suas características pessoais.

A SSD é definida pelo espaço do indivíduo no sistema de relações interpessoais e sociais, sua posição objetiva e o sistema de expectativas e exigências impostas pelo ambiente social: a família, a escola, os amigos e demais espaços sociais que são fatores importantes que definem trajetórias individuais de desenvolvimento psicológico (Karabanova, 2010). A SSD regula estritamente todo o modo de vida do indivíduo ou sua existência social e demonstra as consequências que o rodeiam por toda a vida.

Nessa direção, decidiu-se, para este estudo, por participantes com TEA em sua fase adulta, relacionado ao fato de que as respostas para inúmeras interrogações sobre as suas vivências escolares podem ser encontradas nessa faixa etária, em virtu de de dados de uma trajetória mais ampla de vida. Concentrar-se nas narrativas desses indivíduos nessa faixa etária oportuniza o levantamento de diversos problemas de investigação acerca das suas necessidades e dificuldades ao longo das suas vidas (Chamak et al., 2008). Miller et al. (2017) defendem ainda que é imperativo direcionar estudos para os adultos, à medida que a população com TEA cresce e chega a idade adulta ou envelhecem.

Das pesquisas existentes, constata-se que são outros os que produzem os discursos, como, por exemplo, familiares e profissionais, resultando em escassez de estudos em que indivíduos falam por si, narrando as suas percepções (Bittencourt \& 
Fumes, 2020). Além do mais, as investigações têm focado, historicamente, no TEA na infância, com escassez de pesquisas em adultos, as quais são relativamente negligenciadas (Hickey; Crabtree \& Stott, 2017; Miller et al., 2017; Chen et al., 2015). Semelhantemente, Benham e Kizer (2016) ressaltaram que as narrativas da experiência autística são frequentemente ditas, interpretadas e atribuídas por pessoas que não tem essa condição, permitindo que compreensões culturais dominantes do TEA permeiem sem consulta dos próprios. Em seu estudo, Bittencourt (2018) promoveu as narrativas de pessoas adultas com TEA, apoiadas na tecnologia assistiva SCALA, acerca de todos os seus espaços de vida: nas relações com a família, com o Centro de Atenção Psicossocial em que realizavam acompanhamento, com a escola e/ou Universidade/Faculdade, com o trabalho e em como esses indivíduos se percebiam e o que pensavam sobre si, sobre o autismo e sobre o seu futuro, defendendo que as suas vivências refletiram nas suas escolaridades e concepções de mundo, com impactos no desenvolvimento, constituição, posição social e nas suas apropriações e atividades no mundo.

De forma semelhante, a narrativa de vida é um meio de acesso ao conhecimento do contexto histórico-cultural enfatizado por Vygotski, visto que possibilitou apreender, a partir das palavras ou outras formas de expressão pelos participantes, os acontecimentos, representações, concepções, perspectivas e os seus modos de ser/estar/relacionar com o mundo. As narrativas de vida dos participantes emergiram não apenas a história de si, mas a relação com o grupo social, os aspectos dominantes e as tensões presentes em suas vivências.

Acredita-se que ouvir indivíduos com TEA fornecerá aos pesquisadores percepções significativas das suas experiências, inclusive no âmbito das questões educacionais, pois podem existir importantes diferenças entre o que os pais e professores relatam (Dillon; Underwood \& Freemantle, 2014).

Chiote (2013) considera que conhecer a trajetória escolar e de vida da pessoa com TEA, possibilita reflexões sobre como esse ser social se constituiu, o que aprendeu e como se desenvolveu a partir das relações e interações que lhes foram possibilitadas e das práticas em que foi inserido.

Deste modo, este estudo teve como objetivo analisar as vivências escolares de pessoas adultas com TEA através de narrativas em primeira pessoa, no intuito de contribuir para um melhor entendimento dos aspectos que potencializaram e/ou fragilizaram o prosseguimento ou interrupção da escolaridade.

\section{Método}

Trata-se de uma pesquisa de abordagem qualitativa. Nessa perspectiva, Gray $(2012$, p.135) afirma que "[...] o papel do pesquisador é obter um panorama profundo, intenso e 'holístico' do contexto em estudo, muitas vezes envolvendo a interação dentro das vidas cotidianas de pessoas [...]", sendo esta indicada por Hickey, Crabtree e Stott (2017) como um importante caminho para facilitar o estudo aprofundado das experiências e opiniões de adultos com TEA. Utilizou-se como técnica, a entrevista narrativa. A entrevista narrativa captura as dimensões pessoais e humanas através de histórias vividas e contadas (Clandinin \& Connelly, 2015). As narrativas de vida descrevem a experiência vivida, enriquecendo-a e permitindo apreender as lógicas da ação em seu desenvolvimento biográfico e as configurações de relações sociais em seu desenvolvimento histórico (Bertaux, 2010).

O uso de uma metodologia de auto relato é importante para uma compreensão das questões educacionais ou de vida diretamente sob a perspectiva dos envolvidos (Dillon; Underwood \& Freemantle, 2014). Esses autores reforçam que é errônea a suposição de que pessoas com TEA são incapazes de envolverem-se na autorreflexão, sendo alguns capazes de pensar sobre situações dentro e fora da escola, demonstrando uma autoconsciência que historicamente não lhe é associada.

Essa pesquisa foi aprovada pelo Comitê de Ética em Pesquisa da Universidade Federal de Alagoas (UFAL) sob parecer no $1.340 .279 / 2015$. 
O estudo foi realizado com 4 (quatro) indivíduos diagnosticados com TEA, com idades entre 30 e 36 anos, sendo três do sexo masculino e um do sexo feminino que estavam cadastrados em um CAPS do município de Maceió-Alagoas. De forma a preservar a identidade dos participantes com TEA, foi-lhes solicitado escolher um nome fictício, são eles: Felipe, Nek, Juliana e Melvin.

As entrevistas com os participantes com TEA sobre as suas vivências escolares, aconteceram entre os meses de abril e maio de 2016. Utilizou-se a seguinte questão: Me relate as suas vivências escolares. Essas entrevistas foram realizadas, em momento único, presencial e individual, a sós com a pesquisadora, com duração correspondendo a um tempo mínimo de dezoito minutos e máximo de vinte e nove minutos livremente determinado pelos participantes, considerando as suas narrativas

E, dada a diversidade de diferenças de comunicação experimentadas pelos indivíduos com TEA (Hickey, Crabtree \& Stott, 2017), há desafios inerentes ao uso de metodologias de pesquisa baseadas em entrevistas, especialmente a aberta e a conversação. Nesse sentido, optou-se em também fazer uso do Sistema de Comunicação Alternativa para Letramento de Pessoas com Autismo (SCALA) (http://scala.ufrgs.br), uma tecnologia assistiva, como apoio para que o processo comunicativo com os participantes com TEA acontecesse, pois Passerino e Bez (2015, p. 32) apontaram "progressos pelos sujeitos com autismo quando se aplica algum sistema de comunicação alternativa". Do mesmo modo, Ribas e Gomes (2020) apontaram as potencialidades do SCALA em seu estudo.

O módulo do SCALA utilizado foi o de Narrativas Visuais, destinado para a construção de histórias, através de imagens e outros elementos que disponibiliza. Com eles, os participantes puderam produzir suas histórias sobre a escola. Para Vygotski (1925/2001) as manifestações artísticas possibilitam, a partir das imagens representadas, adentrar os sentimentos e relações do indivíduo em seu meio despertados por intermédio da vivência que a arte promove.

Os dados produzidos foram analisados observando-se as premissas do método em Vygotski (1931/2012) e utilizou principalmente como unidade de análise vivência (Perejivanie). As situações e o conjunto de condições foram analisados em movimento com o desenvolvimento histórico-cultural em que se constituíram os participantes com TEA, na unidade de suas relações sociais e nos posicionamentos em torno do ambiente social.

\section{Resultados e Discussão}

Os indivíduos ingressaram na escola regular na década de 1980, um período, de acordo com Leandro e Lopes (2017), em que a consecução de direitos para indivíduos com TEA no Brasil esteve relacionada diretamente ao engajamento de seus familiares. Esses movimentos promoveram a discussão acerca da inserção e integração das pessoas com deficiência na sociedade. E a luta pelos seus direitos individuais e sociais levou a instituição de políticas, principalmente no tocante ao acesso à educação, a exemplo dos marcos legais da Constituição da República Federativa do Brasil de 1988 e do Estatuto da Criança e do Adolescente de 1990 que lhes garantiam atendimento educacional especializado preferencialmente na rede regular de ensino (Brasil 1988; 1990).

Nesse contexto, os participantes com TEA ingressaram na escola regular em idades variadas: Felipe por volta dos dois anos e meio, Nek com um ano e oito meses, Juliana aos três anos e Melvin aos cinco anos. As instituições privadas foram as principais eleitas nestas trajetórias, com exceção de Felipe que a partir da quarta série ${ }^{1}$ estudou exclusivamente em escolas públicas por razões financeiras da família na época.

Eu estudei a minha vida toda em escola normal [regular] [...]. Também porque não era o diagnóstico certo né? [...]. E assim eu tive o meu desenvolvimento normal (Felipe).

\footnotetext{
${ }^{1}$ Atualmente, quinto ano do Ensino Fundamental.
} 
Em seu relato, Felipe expressou as suas concepções a respeito de ter estudado em escolas regulares porque o seu diagnóstico não estava definido e que por isso, no contexto dessa realidade de ter sido inserido na escola regular, desenvolveuse de forma habitual. A propósito disso, Vygotski (1924/1997a) explicou que em condições favoráveis para o desenvolvimento, o indivíduo vai perdendo os recursos da defectibilidade e um novo caminho é construído, porque o desenvolvimento se diferencia conforme o conjunto de condições em que se realiza. Isso revela a importância de salas de aulas heterogêneas, que por sua diversidade amplia as possibilidades da interação, e que por sua vez contribui para o desenvolvimento das pessoas com deficiência.

Todos vivenciaram consecutivas mudanças de escola, por diversos motivos, ainda que o principal deles diz respeito à fragilidade do sistema escolar em lidar com eles em suas diferenças.

Percebeu-se que os primeiros desafios para a escolarização se relacionavam à matrícula desses participantes, pois quando os responsáveis pelas escolas tomavam conhecimento de suas características e especificidades, tanto se negavam a matriculá-los, como produziam empecilhos para que as mães desistissem. A alegação de que a escola regular não era um lugar adequado para a inserção deles foi recorrente.

Reconhecendo estes argumentos, a mãe de Felipe optava por não informar sobre essas questões no ato da matrícula, avisando somente no primeiro dia de aula, quando já tinha garantida a inserção do seu filho na escola. As demais mães comunicavam previamente e enfrentavam muitas dificuldades para inseri-los no espaço escolar. Estas dificuldades ocorriam mesmo que a Lei $n^{\circ} 7.853$, de 1989, já dispusesse sobre a criminalização deste tipo de comportamento com reclusão e multa (Brasil, 1989). Nesse período, Leandro e Lopes (2017) identificaram também que os profissionais não aceitavam os alunos com deficiência por não identificarem perspectivas para eles.

Superado este primeiro obstáculo, a matrícula destes sujeitos não era suficiente para a garantia à educação. Era exigido de suas famílias o pagamento de taxas extras, por causa das suas especificidades e para que lhes fossem disponibilizados professor exclusivo e uma assistência mais individualizada. Este tipo de acompanhamento foi avaliado como tendo trazido implicações negativas para o desenvolvimento de Juliana que regrediu, visto que não lhe possibilitavam a interação e a independência na realização das atividades, de acordo com o que foi relatado por sua mãe.

Outros desafios relacionavam-se às dificuldades dos professores para mantê-los nas atividades em sala de aula. Felipe, por finalizar rapidamente as tarefas e já ter conhecimento do que era explanado pela professora, ficava impaciente e acabava atrapalhando o desenvolvimento das aulas por adiantar as explicações; Juliana e Melvin ficavam inquietos na sala de aula e também incomodavam professores e colegas, enquanto que Nek acompanhava as aulas mantendo-se quieto e por isso nunca incomodou em sala de aula.

Eu aprendo as coisas muito rápido! Terminava rápido a tarefa, aí eu ficava sem fazer nada e ficava impaciente. Aí eu saí da escola [momento de pausa e entristeceu-se] (Melvin).

Nessa narrativa, Melvin expressou seu sentimento de tristeza com a situação de ter saído da escola, atribuindo à sua rapidez na finalização das tarefas e à sua inquietude em sala de aula por não ter outras atividades a realizar. Isso revela muito sobre o tipo de aluno que é esperado pelos professores. Conforme Vygotski (1929/1997b), há expectativas de determinados tipos ideais de comportamentos, embora os seres humanos, de uma maneira geral, sejam complexos e com dificuldades e habilidades diferentes. Karabanova (2010) também apontou para a expectativas de um conjunto padrão de forma ideal de desenvolvimento que atenda às exigências e competências sociais. Em virtude disso, Felipe mencionou que os professores não eram muito preparados para lidarem com um aluno com deficiência, devido à escassez de conhecimento à época. Uma dificuldade também identificada por ele nos dias atuais: 
Os professores não eram muito preparados, porque naquela época né? Muita pouca coisa sabia em como lidar com aluno especial. E ainda hoje é assim! (Felipe).

Naquele período, a Lei de Diretrizes e Bases da Educação Nacional de 1996 estabelecia que os sistemas de ensino deveriam assegurar currículos, métodos, técnicas, recursos educativos e professores especializados no atendimento das necessidades desses educandos e sua integração nas classes comuns (Brasil, 1996). Semelhantemente, a falta de conhecimento dos profissionais para lidarem com indivíduos com TEA também foi relatada no estudo de Miller et al. (2017) desenvolvido nos Estados Unidos.

A inquietude em sala de aula de Felipe, Juliana e Melvin levou ao uso de uma estratégia constante pelos professores: a condução para a biblioteca da escola e/ou deixá-los perambulando no pátio sem a realização de atividades escolares junto aos colegas de turma, causando constrangimento às mães e tristeza aos participantes:

Eu não gostava de ficar sem fazer nada. Eu gosto de estudar! Eu gosto de aprender! (Melvin).

Nesse relato, Melvin expressou, como disse Vygotski (1934/2010), a sua relação afetiva com esse acontecimento: o seu sentimento de não gostar da ociosidade que lhe era imposta pelos professores em razão da dificuldade deles em lidar com os seus comportamentos. Mencionou ainda a sua afetividade pelo gosto de estudar e aprender, revelando a sua necessidade educacional que o sistema de ensino não foi capaz de lhe proporcionar. Buemo et al. (2019) também disseram que, no contexto escolar, os déficits na comunicação e interação social de pessoas com TEA, causam prejuízos no seu desenvolvimento socioeducacional.

A resposta de Felipe a esta exclusão de sua sala de aula, era a de entrar discretamente na de outras turmas mais avançadas do que a dele para participar dos assuntos mais complexos das disciplinas, pois isso lhe despertava mais interesse.

$\mathrm{O}$ isolamento e as atividades segregadas foram apontadas como fator negativo pelos participantes com TEA da pesquisa de Miller et al. (2017). Por outro lado, Gulec-Aslan, Ozbey e Yassibas (2013) e Dillon, Underwood e Freemantle (2014) defenderam que práticas inclusivas aumentam as possibilidades para alunos com TEA, sendo necessárias oportunidades de interação social para a aprendizagem e desenvolvimento.

Apesar dessas dificuldades para serem escolarizados, os participantes possuíam um bom relacionamento com os colegas das suas próprias turmas, inclusive esses colegas realizavam tentativas para incluí-los no grupo. A exemplo, Felipe expressou seus sentimentos positivos de orgulho quanto ao seu desempenho acadêmico:

Eu nunca repeti de ano. Sempre tirava notas boas, assim, todo mundo queria fazer trabalho comigo, queria fazer prova comigo (Felipe).

Entretanto, em algumas escolas e turmas, os participantes com TEA vivenciaram preconceito e sofreram bullying, o que lhes deixou marcas doloridas fazendo com que não quisessem relatar essas experiências. Estas situações possuem relação com o que foi explicado por Vygotski (1916/1999) a respeito do drama interno que transcorre em silêncio, em que os indivíduos não narram, mas há um sofrimento submerso:

Se for pra lembrar também não gosto! Não gosto de ficar lembrando sabe? Página virada, bola pra frente! De uma forma geral eu me sentia bem na escola. Sempre fui muito bem acolhido e não sofri nenhum tipo de discriminação (Felipe). 
Porém, o bullying sofrido por Felipe, na fase da sua adolescência e durante a realização de um curso técnico especializado, lhe trouxe como consequência a resistência e a não aceitação para a realização de outros cursos técnicos. Percebese que a situação do bullying é corriqueira nas vivências de diversas pessoas com TEA. Hickey, Crabtree e Stott (2017) e Turcotte et al. (2015) identificaram que ser diferente, na fase da infância e adolescência, também incitou experiências de bullying com os participantes com TEA. Para Dillon, Underwood e Freemantle (2014) e Preece e Jordan (2010), estudantes com TEA tornam-se alvo de bullying, devido aos seus comportamentos como hiperatividade, ansiedade, dificuldades de comunicação e para o estabelecimento de amizades.

Em virtude de todas essas dificuldades enfrentadas e pelas constantes reclamações recebidas pelas mães quanto ao comportamento dos filhos, em que os próprios profissionais não sabiam como lidar com as especificidades deles, as mães sempre optavam por mudá-los de escola na tentativa e esperança de contribuição para o desenvolvimento deles.

Em algumas situações, evidenciou-se que escolas pequenas em sua estrutura possibilitaram vivências mais positivas para os participantes e para o seu desenvolvimento, com mais acolhimento, proteção, segurança, atenção e acompanhamento mais específico e mais próximo a eles, apesar da persistência de dificuldades no que diz respeito às estratégias pedagógicas. A preferência por escolas menores foi apontada também pelo estudo de Dillon, Underwood e Freemantle (2014), que mencionaram serem mais conhecidos e conhecerem melhor as demais pessoas.

O prosseguimento dos participantes em sua escolarização foi consequência, principalmente, da mobilização/insistência das mães para permanência deles nas escolas e da parceria delas com as professoras na busca por estratégias que facilitassem a manutenção deles em sala de aula. Nesse sentido, como disse Jannuzzi (2012), a história da educação de pessoas com deficiência se desenvolveu através de tentativas práticas próprias, diante dos desafios que elas se defrontavam nos diversos tempos e lugares.

Felipe e Nek seguiram na idade esperada para cada série. Porém, Juliana e Melvin sofreram atrasos devido aos períodos em que ficaram afastados da escola em virtude da fragilidade do sistema escolar para a inclusão deles. Melvin foi o único que vivenciou parte de sua escolarização na escola especial, principalmente porque sua mãe já não mais aguentava os empecilhos impostos para sua matrícula na escola regular. De acordo com o que foi dito por sua mãe, algumas escolas especiais não foram atrativas para Melvin, causando-lhe desinteresse e pedido para sair.

O período de afastamento/interrupção escolar produziu consequências tanto no desenvolvimento, quanto na carência dos participantes, pois eles sentiam necessidade da escola, dos amigos e de acompanharem os irmãos. A saída da escola lhes causou rupturas no vínculo com os amigos, pois, para os participantes, era o único lugar em que compartilhavam e interagiam com eles. Isso foi evidenciado nas narrativas de Juliana que significou a importância do espaço escolar na sua vida, pela expressão de tristeza por ter saído da escola e pelo afastamento dos professores e dos amigos com os quais tinha um vínculo, além da necessidade de conviver com seus amigos da escola:

Eu fui liberada por mim mesma do colégio, deixei os meus amigos sozinhos sem mim [...]. Eu não posso abandonar os meus amigos. Se eu abandonar os meus amigos vai ficar terrível para mim... [momento de pausa, baixou a cabeça e entristeceu-se]. Os professores já estão com saudade de mim no colégio, os amigos também! Aífica difícil se... eu for liberada de novo e os amigos me segurar para eu não sair (Juliana).

Por isso, Juliana manifestou seu sentimento de interesse pelos estudos, a sua concepção de que não deveria ter saído da escola e o seu desejo de voltar a estudar. E Melvin também relatou sobre a sua tristeza por ter saído da escola, pois não tinha do que não gostar nesse espaço: 
Eu não deveria ter saído de lá! Gosto de estudar. Queria voltar né? [...] Se dependesse de mim, eu voltava para ficar por lá o tempo todo da minha vida (Juliana).

Eu não tinha o que não gostar na escola. Fico triste porque saí da escola. Eu fico assim... impaciente e com tristeza... tudo isso! Mas amanhã eu vou estar bem! (Melvin).

São as consequências sociais, referidas por Vygotski (1929/1997b), da SSD: as rupturas dos vínculos com as pessoas, seu lugar no mundo e do seu papel como partícipe da vida. A concepção de Juliana, de que não deveria ter saído da escola, revelou o que foi dito por Costas e Ferreira (2011) que os indivíduos internalizam significados a partir do social, nas exigências da escolaridade e de estar inserido no sistema escolar. Portanto, conforme também explicou Daniels (2011), a voz social se converteu na voz interior de Juliana, ao internalizar os significados e transformá-los em sua subjetividade. Seu discurso é proveniente dessas exigências sociais.

Outro vínculo de Juliana quanto à escola foi demonstrado quando informou sobre o ato de guardar seu uniforme como objeto de lembrança:

\section{Eu tenho as minhas três camisetas do colégio guardadas de lembrança e uma calça. Foi muito bom! (Juliana).}

Identifica-se sua afetividade com relação a escola através da necessidade de guardar seu uniforme e de preservá-lo, desvelando a importância do espaço escolar em sua vida. A partir das narrativas de Juliana, percebeu-se sua frustração e sua tristeza em relação ao fato de não ter terminado a escola. Ela demonstrou o quanto queria estudar, aprender e prosseguir, mas o sistema escolar não foi capaz de atendê-la em suas necessidades.

Melvin e Nek também afirmaram outros sentimentos quanto à escola e às atividades que realizavam. Ambos também gostavam da escola, dos professores, dos colegas de turma e das amizades. Melvin mencionou o gosto pelo aprendizado, esportes, atividades teatrais, comunicação com os amigos, passeios, merenda e diversão no espaço escolar:

Eu gostava! Gostava dos professores, dos colegas. Eu gostava de aprender, gostava de me divertir bastante. Conversava... gostava dos esportes, dos passeios da escola, de aprender teatrinho, da merenda (Melvin);

Gostava dos professores da escola. Tinha um amigo (Nek).

Percebe-se as afetividades dos participantes com TEA com a SSD que incluía, entre as diferentes esferas de relações citadas por Karabanova (2010), a escola, os professores e a interação com os amigos. De acordo com essa autora, essas relações são importantes por definirem trajetórias individuais de desenvolvimento, mas foram afetadas pela interrupção de sua escolarização.

De igual modo, opiniões positivas quanto aos colegas, os apoios e a atenção pelos professores para a aprendizagem foram apresentadas por pessoas com TEA nos estudos de Gulec-Aslan, Ozbey e Yassibas (2013) e Dillon, Underwood e Freemantle (2014), fazendo-as sentirem-se confortáveis e confiantes, do mesmo modo que professores que ofereciam pouca interação eram vistos de forma negativa.

De acordo com Dillon, Underwood e Freemantle (2014) e Bittencourt \& Fumes (2017), o fato de terem poucos amigos como fonte de apoio social e acadêmico foi destacado como sentimento negativo pelos participantes com TEA. Preece e Jordan (2010) indicam que é raro que estes vejam seus amigos fora desse contexto. 
De modo inverso, Nek se queixou de uma das suas turmas do ensino médio, por conta do barulho e da bagunça dos colegas que jogavam bolas de papel durante as aulas:

Não gostava. Só era zoador que tinha lá. Meus colegas jogavam bola de papel durante as aulas, as vezes em mim também (Nek).

Essa queixa quanto ao barulho e conversas em sala de aula foi também mencionada como fator negativo nos estudos de Dillon, Underwood e Freemantle (2014) e Preece e Jordan (2010) por confundir e prejudicar os indivíduos com TEA no entendimento das atividades.

Nas produções dos participantes estão suas vivências nesse espaço escolar, de acordo com a Figura 1:

Figura 1 - A escola para os participantes com TEA.

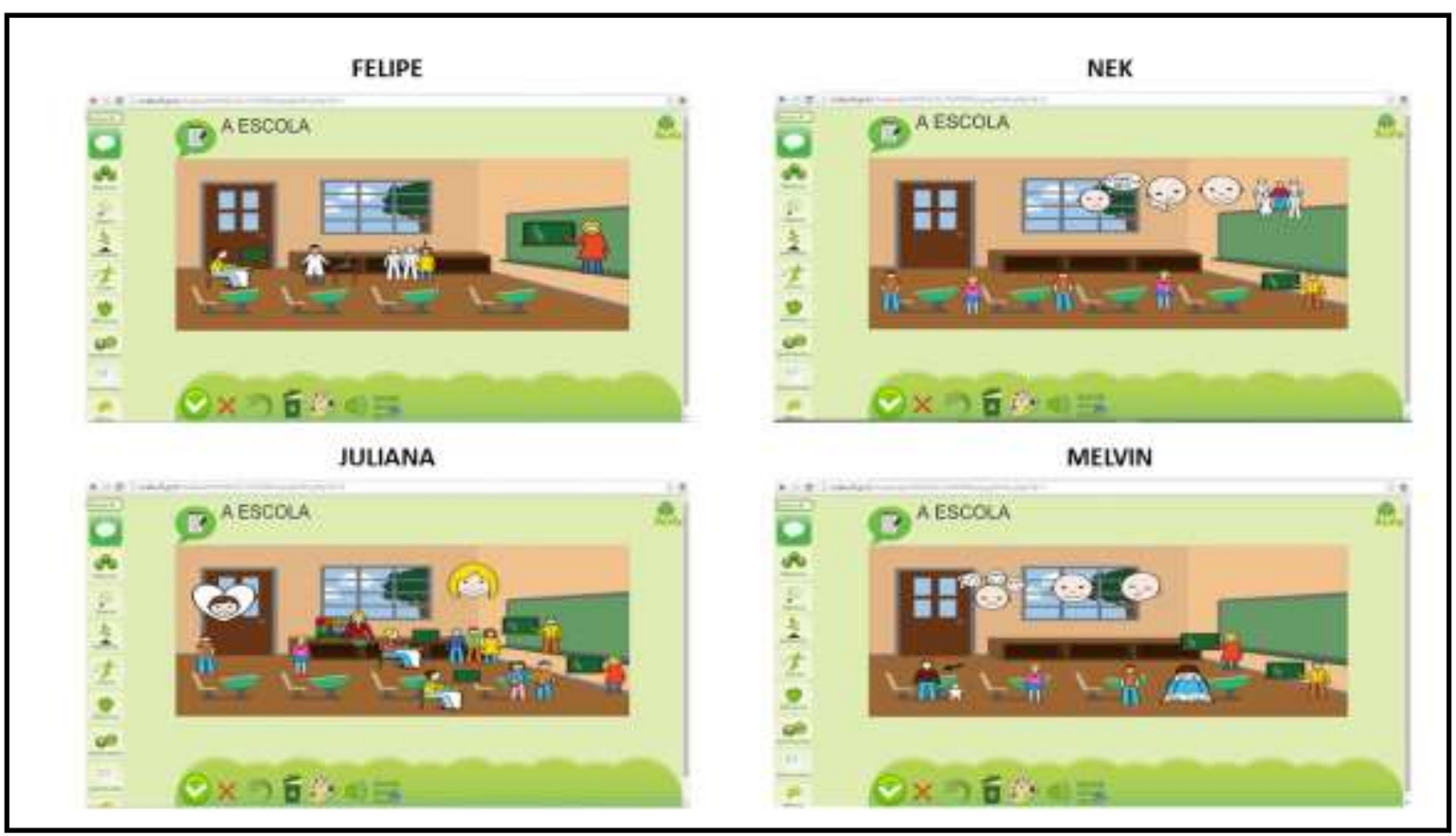

Fonte: Elaborado pelos participantes através do SCALA.

O cenário de sala de aula foi o mesmo escolhido por todos os participantes, que ainda incluíram a si nesse ambiente, seus colegas de turma e professores.

Os sentimentos foram expressos nas histórias de Nek, Juliana e Melvin, que relataram que se sentiam muito felizes na escola, principalmente devido ao contato com os colegas. Nek, ao contrário, se sentia entediado com as aulas de Matemática porque considerava-las difícil. Por sua vez, Melvin disse que gostava dessa matéria, ainda que em algumas ocasiões ficava cansado por serem desagradáveis as aulas.

Eu me sentia muito feliz na escola (Juliana);

Era difícil a matemática, ficava com tédio. Às vezes feliz, quando tava com meus colegas (Nek);

Eu gostava de estudar matemática! As vezes era desagradável e ficava cansado. Mas ficava feliz (Melvin). 
Sobre os sentimentos com relação às aulas de matemática, alude-se que as estratégias pedagógicas utilizadas não foram suficientemente atrativas e direcionadas à diversidade dos alunos e, como consequência, não possibilitaram a compreensão e a aprendizagem desses participantes. Isto foi apontado na pesquisa de Dillon, Underwood e Freemantle (2014), sobre a necessidade de explanação dos conteúdos e atividades de forma clara pelos professores. Mas, apesar dessas dificuldades, Nek, Melvin e Juliana expressaram felicidade pela convivência com os colegas de turma. Essa relação indivíduo-meio, sua SSD, permite, conforme explicou Vygotski (1932/2012d), mudanças dinâmicas que se produzem no seu desenvolvimento, tais como, novas propriedades da personalidade e trajetórias. Ratificando a importância da relação e interação com amigos como fonte de apoio ao desenvolvimento de pessoas com TEA.

Outros espaços da escola foram destacados nas produções de Juliana e Felipe. Juliana simbolizou a biblioteca e a profissional que a recebia nas situações de exclusão das atividades de sala e por isso mencionou sua predileção por esse espaço:

\section{Eu adorava a biblioteca! (Juliana)}

E, Felipe representou o laboratório e relatou a importância da escola em sua vida, por ser um espaço de estudo, aprendizado e de construção de amizades. Manifestou o seu sentimento de gratidão pelas suas vivências na escola e destacou que mantinha contato nos dias atuais com uma das professoras do Ensino Médio:

A escola é importante! É onde eu estudo. É o lugar onde a gente faz as amizades. Eu sou grato! Tem professora, do ensino médio, que até hoje a gente tem contato (Felipe).

Isso revelou a afetividade de Juliana e Felipe pelos demais espaços da escola. De acordo com o que orientou Vygotski (1933/2012b), de se buscar compreender o significado da relação dos indivíduos com de determinados espaços, alude-se que os significados que a biblioteca e o laboratório tinham para eles, era, para Juliana, o de acolhimento nas situações de exclusão das atividades de sala e, para Felipe, de possibilidade de novas descobertas de aprendizagem.

Nesse contexto da SSD dos participantes, Melvin foi o único que não concluiu o ensino médio, devido às inúmeras dificuldades impostas pelo sistema escolar para sua permanência. Juliana concluiu o ensino médio aos vinte e cinco anos, porém não possuía certificado de conclusão em virtude do acordo imposto pela escola de que nada fosse exigido para que lhe aceitasse. Nek concluiu aos dezesseis anos e Felipe aos dezoito anos e ambos prosseguiram para o ensino superior.

Portanto, percebeu-se que as trajetórias de escolarização desses participantes têm relação com as suas vivências, sendo multideterminadas pela realidade social e por sua historicidade. Um período em que se identificou o despreparo do sistema escolar e da sociedade para o trato com as pessoas com deficiência e com TEA no Brasil e de mães protagonistas na transformação das impossibilidades impostas pelo sistema.

Deste modo, o percurso escolar dos participantes com TEA foi mediado pela mobilização das mães para a matrícula, permanência e prosseguimento deles na escola, mas sob diversas interferências da SSD: as consecutivas mudanças de escola por resistência e fragilidade do sistema escolar em lidar com eles em suas especificidades, a insegurança de professores resultante da escassez de conhecimento e formação à época, o isolamento e atividades segregadas pela não identificação de perspectivas para esses indivíduos entre outras situações vivenciadas.

Apesar dos sentimentos positivos e afetividade dos participantes com relação à escola, professores e amigos, do interesse deles pelo aprendizado e do desejo de permanecerem e prosseguirem na escolarização, as interferências produziram consequências definindo as trajetórias escolares e de desenvolvimento de cada participante com TEA. Nesse sentido, o 
desenvolvimento dos participantes coincidiu com a época cultural e com seus fundamentos históricos e possuiu relação, segundo enfatizou Vygotski (1916/1999), com a vida que lhes foi proporcionada e com a inadaptação aos seus ambientes socioculturais.

Mesmo a partir de todos os movimentos e das políticas para integração e posteriormente inclusão escolar das pessoas com deficiência, evidenciou-se, à época, a contradição inclusão/exclusão no processo de escolarização dos participantes com TEA, em consequência, como dito por Orrú (2012), da sua história, realidade social e de práticas fragmentadas e/ou firmadas nas suas limitações.

\section{Considerações Finais}

As vivências de Felipe, Nek, Juliana e Melvin revelaram, cada uma em sua singularidade, ao mesmo tempo com acontecimentos comuns, os enfrentamentos em diferentes momentos da vida que refletiram no prosseguimento e/ou interrupção das suas escolaridades. A partir do conhecimento das suas vivências escolares foi possível entender os aspectos que potencializaram e/ou fragilizaram seu desenvolvimento e participação social. Além de conhecer os seus desafios e as consequências da exclusão.

Nascidos entre os anos de 1981 a 1987, os participantes vivenciaram um sistema escolar incapaz de lidar com suas especificidades. Por isso, o principal alicerce à época na vida e na constituição desses indivíduos foi o espaço familiar. Pois verificou-se as potencialidades da mobilização das mães para a inserção e inclusão escolar e na vida em sociedade.

A escolarização esteve relacionada aos esforços, sobretudo das mães que lutaram para a permanência deles na escola e se esforçaram no apoio aos professores através de sugestões para integrá-los e mantê-los na sala de aula durante as atividades de ensino. Também houve esforços dos próprios participantes com TEA em prosseguir na escolarização para acompanhar seus irmãos e colegas de turma e pela representação da escola enquanto um espaço que lhes possibilitava a socialização e a construção das amizades inexistentes em outros espaços.

As fragilidades do espaço escolar, que produziram desafios para a escolarização dos participantes, revelaram-se a partir da recusa e/ou dificuldade na matrícula, nos empecilhos interpostos para que as mães desistissem da inserção dos filhos na escola regular e nas dificuldades dos professores quanto as estratégias pedagógicas para esses aprendizes diferentes. Deste modo, a escola precisa estar preparada para recebê-los em suas demandas e necessidades, considerando-se o papel dos espaços educativos na construção dos indivíduos. Sendo necessárias práticas inclusivas, atrativas, direcionadas à diversidade e que permitam possibilidades para os alunos com TEA desenvolverem as suas potencialidades nas instituições escolares em todos os níveis, do fundamental ao superior. Há ainda necessidade de intervenções na preparação dos colegas de turma para a inclusão e respeito às diferenças dos alunos com deficiência.

Além disso, verificou-se que pessoas com TEA podem se envolver como participantes de pesquisas em metodologias de auto relato, pois apresentam potencial, que historicamente não lhe é associado, para a autorreflexão sobre situações que lhes dizem respeito, e em virtude disso raramente são oportunizadas a falarem em primeira pessoa.

Constatou-se que a produção de dados através de ferramentas digitais, a exemplo do que foi alcançado como o uso das imagens do módulo de Narrativas Visuais do SCALA, é um caminho para pesquisas voltadas ao protagonismo desses indivíduos. Utilizar o módulo de Narrativas Visuais do SCALA permitiu aos participantes construir suas narrativas em seus contextos escolares sob trajetórias de diferentes olhares, em meio a SSD e no ordenar e representar a realidade.

Com isso, foi possível dar voz a um grupo que é historicamente excluído e, através de múltiplas estratégias, ouvi-los, contribuindo com informações quanto as suas aflições e os sofrimentos que a exclusão provoca, além das marcas que ela deixou na vida dos participantes. 
Os participantes com TEA do estudo conviveram com a falta de garantia de seus direitos fundamentais, conduzindo-os a vulnerabilidade e a invisibilidade social. Dessa forma, é imperativo o compromisso do poder público para garantir-lhes a dignidade e inclusão social, através de discussão de propostas para que a política se amplie e se complemente como via de apoio às pessoas com TEA e sua família, para engajá-las socialmente e poderem lidar com os desafios inerentes ao TEA ao longo de suas vidas.

É preciso compreender que pessoas adultas com TEA possuem potencialidades para o desenvolvimento, mas que lhes são negligenciadas pela inexistência de políticas públicas para essa faixa etária. Por isso, reflete-se sobre a necessidade do desdobramento de novas pesquisas direcionadas às pessoas adultas com TEA, pois, nessa faixa etária elas são invisibilizadas por não se ter políticas públicas de acompanhamento para depois da escola e que as assegurem uma participação efetiva nas atividades de vida adulta com TEA. Desse modo, tornam-se importantes trabalhos futuros que possibilitem as narrativas pessoais desses indivíduos como fonte de investigação, pois isso parte do reconhecimento enquanto sujeitos de direito, de expressarem suas opiniões e de serem ouvidos sobre assuntos que lhes dizem respeito. Tais estudos proporcionam meios para a expressão de si, comunicar-se em sua singularidade, em sua forma de percepção do mundo, dos seus desejos e inquietações significa aproximálos de si e da sua subjetividade e conhecer efetivamente as suas principais necessidades.

\section{Referências}

Benham, J. L. \& Kizer, J. S. (2016). Aut-ors of our experience: interrogating intersections of autistic identity. Canadian Journal of Disability Studies, 77-113. https://cjds.uwaterloo.ca/index.php/cjds/article/download/298/518

Bertaux, D. (2010). Narrativas de vida: a pesquisa e seus métodos. Natal: EdufrnPaulus.

Bittencourt, I. G. S. (2018). As vivências de pessoas adultas com transtorno do espectro autista na relação com a escolaridade e concepção de mundo. Tese de Doutorado em Educação. Universidade Federal de Alagoas. Centro de Educação. Programa de Pós Graduação em Educação. Maceió.

Bittencourt, I. G. S. \& Fumes, N. L. F. (2020). O cenário das pesquisas no âmbito das experiências de vida narradas por pessoas adultas com TEA. Braz. J. of Develop., Curitiba, 6(7), 47752-47765. 10.34117/bjdv6n7-424

Bittencourt, I. G. S. \& Fumes, N. L. F. (2017). A tecnologia assistiva scala como recurso para produção de narrativas e registro de dados nas pesquisas em educação: uma experiência com pessoas adultas com transtorno do espectro autista. Revista Ibero-Americana de Estudos em Educação- RIAEE, 12(n. esp. 2), 1481-1495. http://dx.doi.org/10.21723/riaee.v12.n.esp.2.1304

Brasil. (1988). Constituição da República Federativa do Brasil de 1988. http://www.planalto.gov.br/ccivil_03/Constituicao/Constituicao.htm.

Brasil. (1989). Lei n. 7.853, de 24 de Outubro de 1989. Coordenadoria Nacional para Integração da Pessoa Portadora de Deficiência - Corde. http://www.planalto.gov.br/ccivil_03/LEIS/L7853.htm.

Brasil. (1990). Lei $n^{\circ} 8.069$, de 13 de julho de 1990. Estatuto da Criança e do Adolescente. http://portal.mec.gov.br/seesp/arquivos/pdf/lei8069_02.pdf.

Brasil. (1996). Lei $n^{o} 9.394$ de 20 de dezembro de 1996 Diretrizes e bases da educação nacional. http://portal.mec.gov.br/seed/arquivos/pdf/tvescola/leis/lein9394.pdf.

Buemo, B., Alli, F., Iracet, J. V., Ribas, L., Pereira, R., Kruel, C. S., Guazina, F. M. N., \& Carlesso, J. P. P. (2019). Autism in the School Context: The Importance of Social Insertion. Research, Society and Development, 8(3), e2783822. https://doi.org/10.33448/rsd-v8i3.822

Chamak, B. et al. (2008). What can we Learn about autism from autistic persons? PsychotherPsychosom, 271-279. https://pubmed.ncbi.nlm.nih.gov/18560252.

Chen et al. (2015). The experience of social participation in everyday contexts among individuals with autism spectrum disorders: an experience sampling study. J Autism Dev Disord, p. 1-12. https://pubmed.ncbi.nlm.nih.gov/26687569

Chiote, F. (2013). Inclusão da criança com autismo na Educação Infantil: trabalhando a mediação pedagógica. Wak, 2013.

Clandinin, D. J. \& Connelly, F. M. (2015). Pesquisa narrativa: experiência e história em pesquisa qualitativa. (2a ed.), Uberlândia: Edufu.

Costas, F. \& Ferreira, L. (2011). Sentido, significado e mediação em Vygotsky: implicações para a constituição do processo de leitura. Revista Iberoamericana de Educación. (55), 205-223. https://rieoei.org/historico/documentos/rie55a09.pdf

Daniels, H. (2011). Vygotsky e a pesquisa. Edições Loyola.

Dillon, G. V., Underwood, J. D. \& Freemantle, L. J. (2014). Autism and the U.K. secondary school experience. Focus on Autism and Other Developmental Disabilities, 1-10. 10.1177/1088357614539833 
Research, Society and Development, v. 10, n. 5, e12610514681, 2021

(CC BY 4.0) | ISSN 2525-3409 | DOI: http://dx.doi.org/10.33448/rsd-v10i5.14681

Gray, D. E. (2012). Pesquisa no mundo real. (2a ed.), Penso.

Gulec-Aslan, Y, Ozbey, F. \& Yassibas, U. (2013). I have lived an autism experience. autism is an interesting disease: the life story of a young man with autism. International Education Studies; 6(1). https://files.eric.ed.gov/fulltext/EJ1067119.pdf

Hickey, A., Crabtree, J. \& Stott, J. (2017). Suddenly the first fifty years of my life made sense: experiences of older people with autism. Autism, 1-11. https://doi.org/10.1177/1362361316680914

Jannuzzi, G. S. (2012). A educação do deficiente no Brasil: dos primórdios ao início do século XXI. (3a ed.), Autores Associados.

Karabanova, O. A. (2010). Social situation of child's development - the key concept in modern developmental psychology.Psychology in Russia: State of the Art, (3), 130-153, 2010. http://psychologyinrussia.com/volumes/pdf/2010/05_2010_karabanova.pdf.

Leandro, J. A. \& Lopes, B. A. (2017). Cartas de mães e pais de autistas ao Jornal do Brasil na década de 1980. Interface: Comunicação, Saúde e Educação. http://www.scielo.br/pdf/icse/2017nahead/1807-5762-icse-1807-576220160140.pdf.

Miller, K. et al. (2017). Program experiences of adults with autism, their families, and providers: findings from a focus group study. Autism, 1-12, 2017. https://doi.org/10.1177/1362361316679000

Orrú, S. E. (2012). Autismo, linguagem e educação: interação social no cotidiano escolar. (3a ed.), Wak.

Passerino, L. M. \& Bez, M. R. (2015). Sobre comunicação e linguagem. In: Passerino, L. M. \& Bez, M. R. Comunicação alternativa: mediação para uma inclusão social a partir do SCALA Ed. Universidade de Passo Fundo.

Preece, D. \& Jordan, R. (2010). Obtaining the views of children and young people with autism spectrum disorders about their experience of daily life and social care support. British Journal of Learning Disabilities. https://doi.org/10.1111/j.1468-3156.2009.00548.x

Ribas, S. G., \& Gomes, G. R. R. (2020). Teacher training for the use of assistive technology through SCALA software: a case study. Research, Society and Development, 9(2), e105922078. https://doi.org/10.33448/rsd-v9i2.2078

Turcotte et al. (2015). Social participation during transition to adult life among young adults with high- functioning autism spectrum disorders. Occupational Therapy in Mental Health, 31, 234-252. 10.1080/0164212X.2015.1051641

Vygotski, L. S. (1999). A tragédia de Hamlet, príncipe da Dinamarca. Martins Fontes. Texto original de 1916.

Vygotski, L. S. (1997a) El defecto y la compensación. Obras escogidas- Tomo V. Visor Dis. S.A. Texto original de 1924.

Vygotski, L. S. (2001). Psicologia da arte. (2a ed.) Martins Fontes. 2001. Texto original de 1925.

Vygotski, L. S. (1997b). Los problemas fundamentales de la defectología contemporánea. In: Obras escogidas- Tomo V. Visor Dis. Texto original de 1929.

Vygotski, L. S. (2012a) Futuras vías de investigación: desarrollo de la personalidade del niño y de su concepción del mundo. In: Obras Escogidas-Tomo III. VIGOTSKI, Lev Semyonovich. Machado Grupo de Distribuição. S.L. Texto original de 1931.

Vygotski, L. S. (2012b). La crisis de los siete años. In: Obras Escogidas-Tomo IV. Vigotski, L. S. Machado Grupo de Distribuição. S.L, 2012b. Texto original de 1933.

Vygotski, L. S. (2012d). El problema de la edad. In: Obras Escogidas-Tomo IV. Vigotski, L. S. Madrid: Machado Grupo de Distribuição. S.L, 2012d. Texto original de 1932 .

Vygotski, L. S. (1997c) La defectología y la teoría del desarrollo y la educación del niño anormal. In: Obras escogidas- Tomo V. Visor Dis, 1997c. Texto original de 1934.

Vygotski, L. S. (2010). Quarta aula: a questão do meio na pedologia. Psicologia USP, 21(4), 681-701. Texto original de 1934. 